\title{
AN ASSESSMENT OF INTRAOCULAR PRESSURE DURING FRACTIONATED PERIBULBAR ANAESTHESIA
}

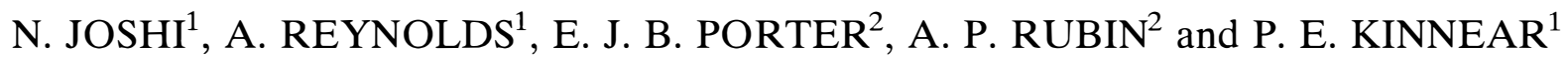 \\ London
}

\section{SUMMARY}

This study of 20 patients undergoing elective cataract surgery was performed to investigate the change in intraocular pressure that accompanies extraconal peribulbar anaesthesia. We have demonstrated that each injection during peribulbar anaesthesia causes a small rise in intraocular pressure. The routine use of conventional external ocular compression overcomes this pressure rise and safely provides a satisfactory and progressive reduction in intraocular pressure prior to surgery. Our findings suggest that the volumes of anaesthetic solutions used in fractional peribulbar anaesthesia, if used in conjunction with external compression devices, result in intraocular pressures acceptable for intraocular surgery.

Extraconal peribulbar local anaesthesia for ocular surgery is a common and acceptable technique for patients, surgeons and anaesthetists. ${ }^{1,2}$ It has rapidly become the preferred technique for ocular surgery in many centres, as the possible grave consequences of intraconal retrobulbar local anaesthesia, including the introduction of local anaesthetic agents into the central nervous system, have now become apparent. ${ }^{3}$

The technique of extraconal peribulbar anaesthesia requires a relatively large volume of anaesthetic solution to be injected into the peribulbar space. This space is confined by the bones of the orbit, and therefore by inference the introduction of fluid into this space should result in a pressure effect on the globe. This study was designed to assess intraocular pressure change during the induction of extraconal peribulbar anaesthesia for cataract surgery using a non-contact tonometer.

From: Departments of ${ }^{1}$ Ophthalmology and ${ }^{2}$ Anaesthetics, Charing Cross Hospital, London, UK.

Correspondence to: Mr N. Joshi, Department of Ophthalmology, Charing Cross Hospital, London W6 8RF, UK.

\section{PATIENTS AND METHODS}

Informed consent was obtained from 20 adult patients undergoing elective cataract surgery under local anaesthesia in this ethically approved study. Patients with a history of glaucoma, trauma or previous surgery to the eye were excluded.

After insertion of an intravenous cannula, anaesthesia was induced following a standardised technique. All solutions were warmed to $37^{\circ} \mathrm{C}$. First $0.5 \mathrm{ml}$ amethocaine $1 \%$ was diluted to $2 \mathrm{ml}$ in balanced salt solution, and instilled into the inferior conjunctival fornix. This was followed after 15 seconds by 3 drops of undiluted amethocaine $1 \%$ drops. Then $1.5 \mathrm{ml} 0.2 \%$ lignocaine (derived from dilution of $2 \%$ lignocaine in balanced salt solution) was injected through a 27 gauge $12 \mathrm{~mm}$ needle into the inferotemporal fornix. The eye was massaged gently by digital pressure for 1 minute and then a Buys bag (Micro-Surgical Technology, USA) was applied for 2 minutes to standardise the pressure applied.

After this 3 minute period, the subsequent injections were commenced, using a $25 \mathrm{~mm} 25$ gauge needle. Each was of $5 \mathrm{ml}$ volume, and contained equal volumes $(2.25 \mathrm{ml})$ of $0.75 \%$ bupivacaine and $2 \%$ lignocaine, with hyalase $37.5 \mathrm{IU}$ and adrenaline $25 \mu \mathrm{g}$. The first of these injections was made in the

Table I. Schedule for measurement of intraocular pressure (IOP)

\begin{tabular}{lcc}
\hline Procedure & $\begin{array}{c}\text { Volume } \\
(\mathrm{ml})\end{array}$ & $\begin{array}{c}\text { IOP } \\
\text { measurements }\end{array}$ \\
\hline Topical anaesthesia & & $\mathrm{P} 1$ \\
Dilute injection & 1.5 & $\mathrm{P} 2$ \\
Massage/bag $(3 \mathrm{~min})$ & 5 & $\mathrm{P} 3$ \\
Injection 1 & & $\mathrm{P} 4$ \\
Massage/bag $(5 \mathrm{~min})$ & 5 & $\mathrm{P} 5$ \\
Injection 2 & & P6 \\
Massage/bag $(5 \mathrm{~min})$ & 5 & $\mathrm{P} 7$ \\
Injection 3 & & P8 \\
Massage/bag $(5 \mathrm{~min})$ & & P9 \\
\hline
\end{tabular}




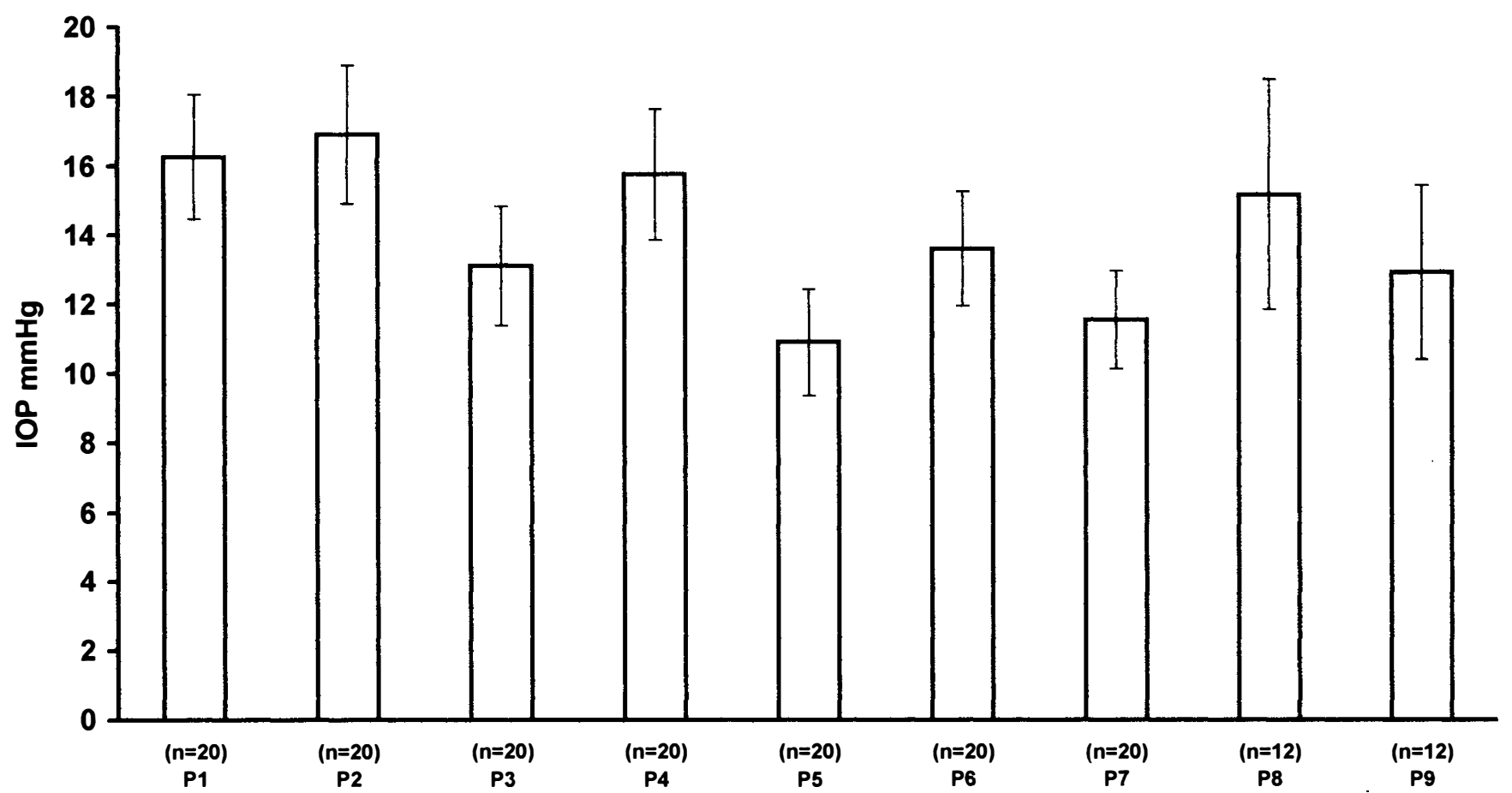

Fig. 1. The changes in intraocular pressure at the beginning of and throughout the study. Mean intraocular pressure (IOP) and 95\% confidence intervals are shown. Readings P1 to P9 are as in Table I.

inferotemporal quadrant, the second in the nasal compartment, and subsequent injections in the quadrant thought most appropriate to achieve complete akinesia. After each injection the eye was massaged digitally for 2 minutes, and the Buys bag was applied for 3 minutes before the next injection was given.

Intraocular pressure measurements were made according to the schedule outlined in Table I. Intraocular pressure was measured immediately before and after each injection until the block was adequate for surgery. All measurements were made by the same operator (N.J.) using a Keeler Pulsair 2000 non-contact tonometer, and the result recorded on each occasion was the mean of four measurements. Drops of normal saline were applied to the cornea to facilitate the recordings as necessary. A non-contact tonometer was preferred to eliminate the risk of traumatic corneal damage and contamination.

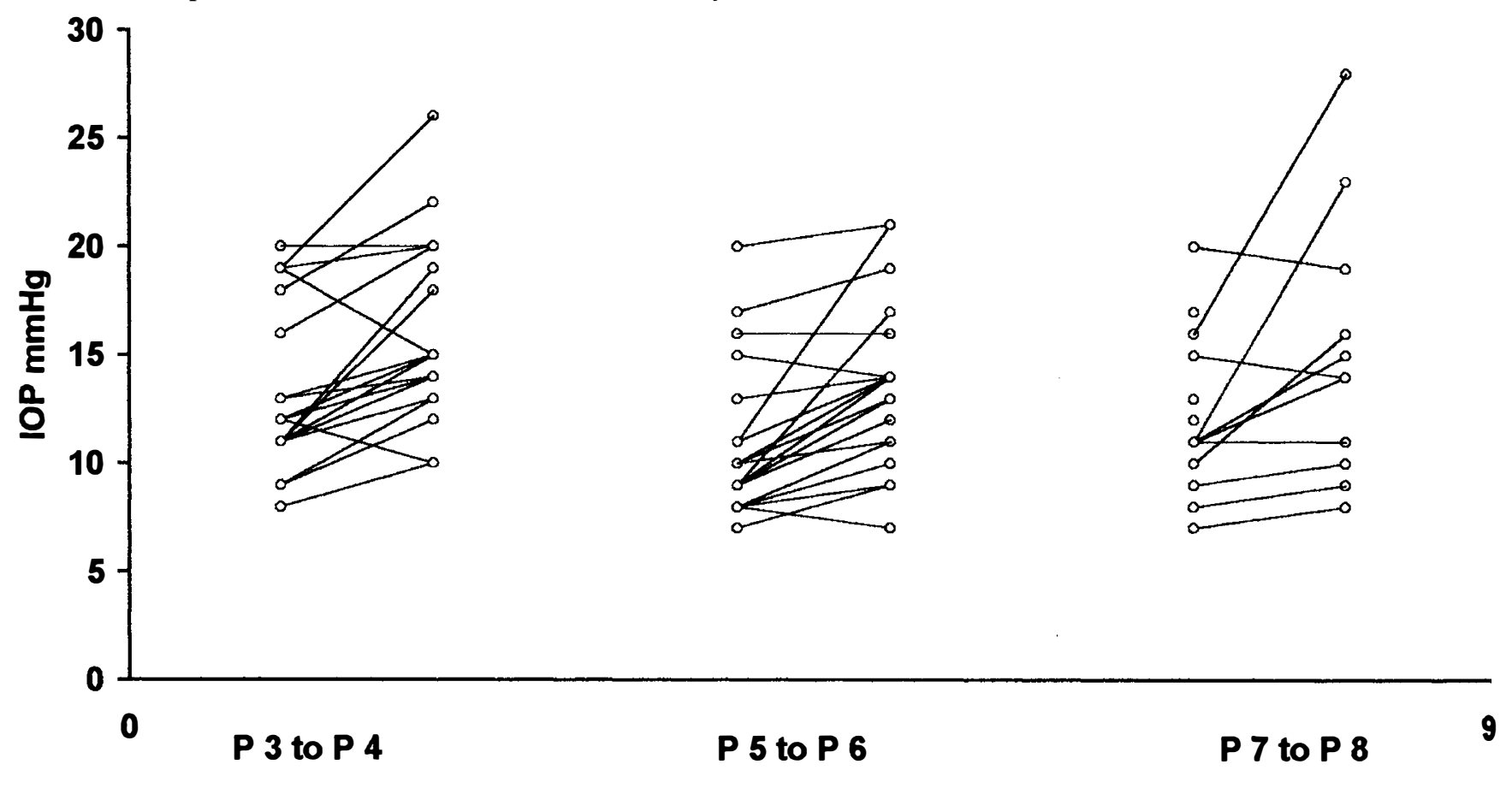

Fig. 2. Effect on intraocular pressure of each $5 \mathrm{ml}$ injection of anaesthetic solution. 


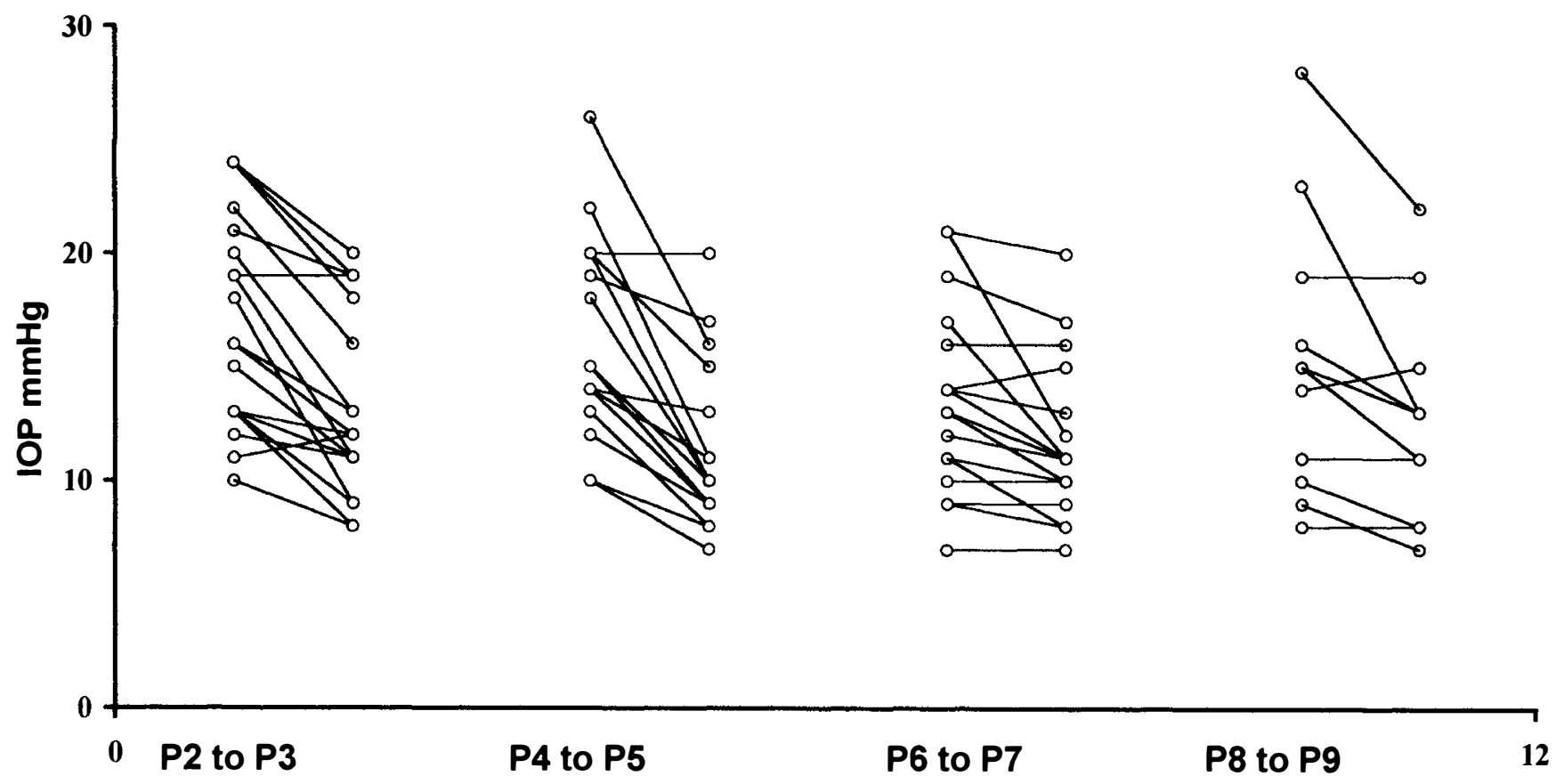

Fig. 3. Effect on intraocular pressure of each application of the Buys bag.

RESULTS

Twenty patients were studied, of which 7 were male (mean age 73.3 years; range $56-83$ years) and 13 were female (mean age 73.4 years; range 45-90 years). All underwent uncomplicated cataract extraction and intraocular lens implantation.

The mean $( \pm 1 \mathrm{SD})$ intraocular pressure at the start of the study was $16.25 \mathrm{mmHg}( \pm 4.08 \mathrm{mmHg})$. The mean $( \pm 1 \mathrm{SD})$ intraocular pressure prior to starting surgery was $12.3 \mathrm{mmHg}( \pm 3.85 \mathrm{mmHg})$. These results are presented in Fig. 1, with mean intraocular pressures and $95 \%$ confidence intervals at each point in the study.

No statistically or clinically significant rise in intraocular pressure was seen when compared with the initial intraocular pressure reading. Multiple comparisons were not made as a cumulative effect could not be excluded. The intraocular pressure measurements are shown in Table II.

Figs. 2 and 3 demonstrate the effect of each $5 \mathrm{ml}$ injection and the Buys bag respectively on the intraocular pressure.

Table II. Intraocular pressure (IOP) readings in 20 subjects

\begin{tabular}{|c|c|c|c|c|c|c|c|c|c|}
\hline \multirow[b]{2}{*}{ Subject } & \multicolumn{9}{|c|}{ IOP reading $(\mathrm{mmHg})$} \\
\hline & P1 & $\mathrm{P} 2$ & P3 & P4 & P5 & P6 & P7 & P8 & P9 \\
\hline 1 & 21 & 24 & 18 & 22 & 11 & 21 & 12 & & \\
\hline 2 & 13 & 13 & 9 & 12 & 9 & 13 & 10 & & \\
\hline 3 & 11 & 12 & 11 & 13 & 8 & 9 & 8 & & \\
\hline 4 & 17 & 16 & 12 & 14 & 11 & 14 & 13 & & \\
\hline 5 & 9 & 10 & 8 & 10 & 8 & 11 & 8 & 9 & 7 \\
\hline 6 & 17 & 16 & 13 & 15 & 9 & 17 & $11^{\circ}$ & 23 & 13 \\
\hline 7 & 23 & 24 & 19 & 26 & 16 & 16 & 16 & 28 & $22 \ldots 17^{\mathrm{a}}$ \\
\hline 8 & 19 & 22 & 16 & 20 & 15 & 14 & 11 & 15 & 11 \\
\hline 9 & 21 & 24 & 20 & 20 & 10 & 14 & 11 & 11 & 11 \\
\hline 10 & 20 & 19 & 19 & 20 & 20 & 21 & 20 & 19 & 19 \\
\hline 11 & 16 & 18 & 9 & 13 & 8 & 10 & 10 & 16 & 13 \\
\hline 12 & 13 & 15 & 11 & 19 & 17 & 19 & 17 & & \\
\hline 13 & 23 & 21 & 19 & 15 & 10 & 13 & 11 & 14 & 15 \\
\hline 14 & 14 & 13 & 11 & 18 & 10 & 11 & 10 & & \\
\hline 15 & 17 & 20 & 13 & 14 & 13 & 14 & 15 & 14 & 15 \\
\hline 16 & 16 & 19 & 11 & 15 & 10 & 13 & 10 & & \\
\hline 17 & 13 & 13 & 12 & 15 & 9 & 14 & 11 & & \\
\hline 18 & 16 & 15 & 11 & 14 & 9 & 12 & 11 & 15 & 13 \\
\hline 19 & 16 & 11 & 12 & 10 & 7 & 9 & 9 & 10 & 8 \\
\hline 20 & 10 & 13 & 8 & 10 & 8 & 7 & 7 & 8 & 8 \\
\hline
\end{tabular}

${ }^{\mathrm{a}}$ The Buys bag was left on for a further 5 minutes, without injections. 


\section{DISCUSSION}

Peribulbar and retrobulbar anaesthesia have been shown to cause an initial rise in intraocular pressure. ${ }^{4}$ Ocular compression can neutralise the effect of the anaesthetic volume resulting in a lowering of intraocular pressure. ${ }^{4-6} \mathrm{~A}$ decrease in intraocular pressure pre-operatively has been shown to be of benefit in surgical outcome.

The non-contact Keeler Pulsair 2000 tonometer was chosen for its ease of use, objectivity, and lack of corneal touch prior to surgery. This instrument has been shown to give acceptable and reproducible results. ${ }^{7,8}$ It proved to be a reliable and uncomplicated device to use, and was acceptable to all the subjects studied.

The Buys bag is a fabric-covered bag containing mercury that exerts a pressure of approximately $25 \mathrm{mmHg}$ when applied to the globe. A rapid initial reduction of intraocular pressure is reached after 10 minutes of use in normal volunteers. ${ }^{5}$

The results demonstrate a variable response to the peribulbar injections. In all cases where a rise in pressure was recorded immediately after an injection, this was eliminated by external compression before the subsequent injection. The net result in most cases was a stepwise reduction in intraocular pressure from the starting value. No injection led to such great rises in intraocular pressure (greater than $30 \mathrm{mmHg}$ ) as have been reported previously; ${ }^{4,6}$ this may be explained by the fractionated method, with the use of ocular compression between injections.

After an injection volume exceeding $11.5 \mathrm{ml}$ there was an upward trend in intraocular pressure, although this is not statistically significant as the number of patients receiving the higher volumes was too small. This trend is counteracted by extraocular compression, and the pressure prior to surgery, after $11.5-16.5 \mathrm{ml}$ of local anaesthetic agent, was always lower than the starting pressure.

Those patients in this study who had initial intraocular pressures in excess of $20 \mathrm{mmHg}$ (subjects 1 and 7) had had pressures below this value when assessed pre-operatively by Goldmann applanation tonometry. The patient with an initial pressure of $23 \mathrm{mmHg}$ (subject 7) reached a peak pressure of $28 \mathrm{mmHg}$; but the pressure prior to commencing surgery was $17 \mathrm{mmHg}$ following external compression.

The pressure-lowering value of external compression has been demonstrated previously. ${ }^{5}$ It is considered that there is an advantage in spacing the several injections required for peribulbar anaesthe- sia, allowing for intermittent external compression to maintain a low intraocular pressure prior to surgery. The advantages of the use of intraocular pressurelowering devices have been described previously. ${ }^{9}$

This study offers reassuring evidence that in spite of the injection of relatively large volumes of local anaesthetic solutions during an extraconal peribulbar block, the small rises in pressures encountered in the normal eye are overcome by the use of gentle massage techniques between injections, and that peribulbar blocks need not contribute to high intraocular pressure through a volume effect. It must be stressed that the patients included in this study had no previous history of a rise in intraocular pressure, where there may be other physiological effects involved. It is possible that prior use of a pressure-lowering device might limit the induced rise in pressure, particularly in the eye with a higher resting pressure. ${ }^{5}$ It would seem advisable to use the pressure-reducing device for longer if high injection volumes are required.

The authors would like to thank Keeler Ltd for the loan of their Pulsair 2000 Tonometer for the purposes of this study.

Key words: Air pulse tonometer, Buys bag, Extraconal peribulbar anaesthesia, Intraocular pressure.

\section{REFERENCES}

1. Hamilton RC, Gimbel HV, Strunin L. Regional anaesthesia for 12000 cataract extraction and intraocular lens implantation procedures. Can J Anaesth 1988;35:615-23.

2. Murdoch IE. Peribulbar versus retrobulbar anaesthesia. Eye 1990;4:445-9.

3. Nielsen L. Respiratory arrest following retrobulbar block. Ugeskrift for Laeger 1990;152:329.

4. O'Donoghue E, Batterbury M, Lavy T. Effect on intraocular pressure of local anaesthesia in eyes undergoing intraocular surgery. $\mathrm{Br} \mathrm{J}$ Ophthalmol 1994;78:605-7.

5. Constable PH, Porter EJB. Extraocular compression prior to cataract surgery: timecourse of reduction and subsequent recovery of intraocular pressure. Eye 1993;7:731-4.

6. Morgan JE, Chandna A. Intraocular pressure after peribulbar anaesthesia: is the Honan balloon necessary? Br J Ophthalmol 1995;79:46-9.

7. Bricker SRW, McGalliard JN, Mostafa SM. The Keeler Pulsair impulse tonometer. Anaesthesia 1990;45:36-9.

8. Vernon SA. Reproducibility with the Keeler Pulsair 2000 non-contact tonometer. $\mathrm{Br} \mathrm{J}$ Ophthalmol 1995;79:554-7.

9. Palay DA, Stulting RD. The effect of external ocular compression on intraocular pressure following retrobulbar anaesthesia. Ophthalmic Surg 1990;21:503-7. 